\title{
Relações entre a aprendizagem autorregulada e os fatos (auto)biográficos
}

\author{
Fabiane Puntel Basso*, Maria Helena Menna Barreto Abrahão*, Lourdes Maria Bragagnolo Frison** \\ *Pontifícia Pontifícia Universidade Católica do Rio Grande do Sul, ** Universidade Federal de Pelotas \\ Brasil
}

\begin{abstract}
Resumo
O objetivo desse trabalho foi verificar a adequação de uma metodologia autobiográfica na compreensão do processo da aprendizagem autorregulada, em alunos do $9^{\circ}$ ano do Ensino Fundamental. Participaram do estudo dez alunos de uma escola da rede pública estadual da cidade de Porto Alegre, Brasil. Foi utilizada uma metodologia de abordagem autobiográfica, inspirada na técnica dos ateliês biográficos de projetos, adaptada aos objetivos da pesquisa. A análise de cada etapa do ateliê mostrou que as experiências de vida de cada aluno revelaram os níveis de autorregulação da aprendizagem e de apropriação das estratégias utilizadas no seu processo formativo.
\end{abstract}

Palabras clave: ateliê biográfico, aprendizagem autorregulada, fatos autobiográficos.

\section{Introdução}

O papel oficial do aluno no percurso escolar é de aprender, adquirir autonomia ao longo da sua escolarização para formar-se como cidadão e para ter uma futura profissão. Mas nessa posição objetiva existe uma correspondência subjetiva que determina a forma pela qual ele se apropria desse papel. O aluno vive de maneira singular sua integração no mundo da escola em função da sua história de vida, das relações com seus colegas, membros da família, professores, etc.

Na escola, grande parte das aprendizagens dos alunos são organizadas pelos professores. No entanto, a aprendizagem pode ser mais eficiente se o aluno conseguir gerenciar ele mesmo parte desse processo, pois é dessa forma que ele deverá fazer durante a maior parte das suas aprendizagens após a escolarização. Por esta razão, os alunos precisam ser capazes de definir metas, de perseverar, de medir seus próprios progressos, de adaptar as estratégias de aprendizagens às circunstâncias e a superar suas dificuldades. Segundo Cosnefroy (2013) os alunos que são capazes de definir objetivos de aprendizagem de maneira autônoma na escola são mais preparados para aprender ao longo de toda a vida.

Se um aluno não tem motivação ou interesse nas atividades de aprendizagem propostas pela escola, ele corre o risco de não desenvolver as capacidades necessárias para adquirir saberes fundamentais, apropriar-se de conceitos essenciais e desenvolver competências importantes. Por este motivo que os aspectos individuais da história do aluno são importantes para entender seu percurso escolar, seus interesses e motivações para aprender. A partir das narrativas dos alunos, é possível compreender como eles fazem uso da aprendizagem autorregulada, se a utilizam nas áreas de maior interesse e quais são as principais estratégias de autorregulação da aprendizagem.

A abordagem autobiográfica de pesquisa auxilia na compreensão desse processo de autorregulação e pode contribuir para fazer emergir as diferentes formas de autorregular a aprendizagem. Essa abordagem procura mostrar a coerência entre o sentido individual e a autorregulação da aprendizagem, buscando apoio no discurso narrativo e na reflexão do sujeito. Nesta perspectiva, a finalidade deste artigo é verificar a adequação do estudo da aprendizagem autorregulada dentro de uma perspectiva autobiográfica, mais especificamente inspirada na técnica dos ateliês biográficos de projetos de Delory-Momberger (2006). Busca-se também, através dos ateliês biográficos de projeto, compreender o processo da aprendizagem autorregulada em alunos do $9^{\circ}$ ano, último ano de estudos do nível Fundamental de Ensino no Brasil, observando como eles percebem-se e constituem-se como agentes da própria formação no cotidiano de experiências de vida e de aprendizagem.

\section{Fundamentos Teóricos}

Não existe aprendizagem sem experiência e sem uma reflexão pessoal, (auto)biográfica, sobre a experiência.

A partir dessa frase de Nóvoa (2012), essa seção do artigo inicia uma apresentação breve desses dois temas de investigação que se entrelaçam na presente pesquisa: autorregulação da aprendizagem e pesquisa (auto)biográfica. $\mathrm{O}$ tratamento metodológico fundamentado na abordagem (auto)biográfica, em especial o uso de ateliês de projetos, amplia e enriquece a potencialidade analítica de trabalhos realizados com o objetivo de compreender o processo de autorregulação da aprendizagem de alunos do Ensino Fundamental.

O construto autorregulação da aprendizagem está relacionado com a capacidade do aluno de criar metas, que incluem saber escolher estratégias específicas, 
favorecedoras do alcance de objetivos, que levem a execução dos planos traçados. Os processos pessoais relacionados com a escola, ativados pela reflexão desvelada nos atelies oferecem aos alunos a possibilidade de encontrar significado e sentido em distintas situações, estimulando a autorregulação do pensar sobre e do aprender a aprender (Frison \& Veiga Simão, 2011).

Para Zimmerman (2000), a aprendizagem autorregulada é a capacidade dos alunos desenvolverem conhecimento, estratégias e comportamentos essenciais para incrementar as aprendizagens, seja no contexto escolar ou nas vivências cotidianas. $O$ aluno se autorregula quando participa ativamente, do ponto de vista cognitivo, metacognitivo, motivacional e comportamental, do seu próprio processo de aprendizagem. Nessa mesma perspectiva, Zimmerman, Bonner e Kovach (2000), afirmam que a autorregulação escolar designa um conjunto de pensamentos, sentimentos e ações geradas pelos alunos para atingir objetivos educativos específicos.

Estudos recentes (Abrahão, 2012, Abrahão \& Frison, 2010, Basso \& Abrahão, 2015, Mottier, 2013) mostram que um aprendiz autônomo é seguidamente descrito como sendo um aluno autorregulado na sua aprendizagem. Dessa forma, a autorregulação visaria uma otimização da aprendizagem e uma melhoração da percepção que os alunos tem da sua própria eficiência e do controle que eles tem sobre os processos de aprendizagem.

O estudo da aprendizagem autorregulada a partir de uma abordagem autobiográfica ainda é pouco observado na literatura. Para Abrahão e Frison (2010) e, igualmente, Frison e Veiga Simão (2011) esse elo entre a aprendizagem autorregulada e a pesquisa autobiográfica é importante para mapear e compreender o processo de autoformação. Segundo essas autoras, o centro da pesquisa autobiográfica encontra-se no ser humano que, em diferentes contextos e situações, se autobiografa, seja narrando fatos da vida ou refletindo sobre o processo de autoformação.

Os estudos de Abrahão (2003, 2004a, 2004b, 2005, 2008, 2012) consideram a abordagem autobiográfica como uma metodologia com potencialidades de diálogo entre o individual e o sociocultural, pois proporciona um diálogo com os contextos e evidencia a maneira pela qual cada pessoa mobiliza seus conhecimentos e valores para formar a sua identidade.

Dentro da abordagem auto(biográfica) pode-se distinguir os ateliês biográficos de projetos, fundamentado nos procedimentos utilizados pela pesquisadora francesa Delory-Momberger (2007) e pela suissa Josso (2004). Essa técnica de pesquisa que instiga o diálogo e a reflexão, procura proporcionar trocas sobre as experiências relatadas, o que permite uma retomada do percurso escolar de formação e autoformação construído por cada um. Assim como Delory-Momberger (2007), Josso (2004, p. 27) também salienta que o trabalho com as experiências vividas é uma oportunidade para o sujeito "caminhar para si”, para a tomada de consciência dos seus percursos pessoais, escolares e profissionais.

Nessa perspectiva, Passeggi, Souza e Vicentini (2011) afirmam que a partir dos ateliês biográficos é possível investigar como os alunos dão forma à suas experiências e sentido ao que antes não tinha, como constroem a consciência histórica de si e de suas aprendizagens nos territórios que habitam e são por eles habitados, mediante o processos de biografização. Assim, conhecer, ouvir, ler sobre as experiências do outro também é um modo de autoformação que pode influenciar positivamente o processo de autorregulação da aprendizagem escolar.

\section{Contextualização da pesquisa}

O estudo foi realizado dentro de uma perspectiva qualitativa, seguindo uma abordagens autobiográfica de pesquisa, inspirada na técnica de ateliê biográfico de projetos. O cenário foi constituído por uma escola Estadual de Ensino Fundamental, localizada na cidade de Porto Alegre, Rio Grande do Sul, Brasil.

\section{Participantes}

Participaram desse estudo dez alunos do $9^{\circ}$ ano do Ensino Fundamental. No total foram seis indivíduos do gênero feminino e quatro do gênero masculino. As idades variaram de 14 anos e 4 meses à 16 anos e 8 meses. Os alunos do $9^{\circ}$ ano foram escolhidos como sujeitos dessa pesquisa por fazerem parte de uma etapa delicada da aprendizagem escolar. Nesse período final do Ensino Fundamental, os alunos aprofundam os conhecimentos adquiridos no ciclo anterior e iniciam os estudos das matérias que serão a base para a continuidade no Ensino Médio. Esta fase é repleta de mudanças, em que os jovens buscam sua autonomia de forma mais intensificada, utilizando a aprendizagem autorregulada como meio para novas apropriações.

\section{Método}

A coleta dos dados da pesquisa foi realizada a partir de uma técnica inspirada no ateliê biográfico de projetos de Delory-Momberger (2006, 2007). Foram realizadas seis sessões em grupos de cinco alunos, com duração em torno de 45 minutos cada uma. Todas as etapas do ateliê foram realizadas no ambiente escolar, em uma sala de aula, durante o período da disciplina de português. Os encontros foram previamente arranjados com a professora de português para se adequar ao planejamento das atividades e não atrapalhar o desenvolvimento da disciplina. As etapas dos ateliês foram adaptadas ao objetivo da pesquisa, acarretando modificações das etapas afim de melhor aprofundar os aspectos relacionados à aprendizagem autorregulada. Assim, as etapas dos ateliês envolveram seis encontros que objetivaram a reflexão sobre as estratégias autorregulatoras na atividade de estudo, a socialização dessas reflexões e a mobilização de novas estratégias autorregulatórias no projeto educacional de cada um. As seis etapas são apresentadas a seguir:

Primeira etapa: encontro com o grupo de professores envolvidos na formação dos alunos do $9^{\circ}$ ano para apresentar o projeto de pesquisa. Houve uma exposição das etapas da pesquisa e discussões em torno do trabalho a ser realizado com os grupos de alunos. Inicialmente era previsto a participação de 20 alunos oficialmente matriculados no início do ano letivo. Entretanto, 
ocorreram quatro transferências de alunos para outras escolas e seis desistências no primeiro mês de aula. Dessa forma, restaram dez alunos frenquentando o $9^{\circ}$ ano do Ensino Fudamental na escola.

Segunda etapa: contato inicial com os dez alunos participantes da pesquisa e estabelecimento de um contrato de participação com informações sobre os procedimentos, objetivos e dispositivos que iriam ser colocados em práticas. Nessa etapa também foram recuperados os termos de consentimento esclarecido e assinados os termos de assentimento para menores.

Terceira etapa: produção escrita de uma narrativa autobiográfica sobre o percurso escolar do aluno, suas dificuldades ao longo da escolarização, as experiências no contexto escolar e reflexões sobre as estratégias pessoais utilizadas no estudo.

Quarta etapa: socialização das autobiografias narrativas e discussão sobre os aspectos que envolvem as experiências escolares e as estratégias autorregulatórias para a aprendizagem. As reflexões foram desenvolvidas a partir de algumas questões previamente formuladas:

$\checkmark$ O que é estudar para ti?

$\checkmark$ Quais os motivos que te levam a decidir começar a estudar?

$\checkmark$ Quando está fora da sala de aula e vais estudar, o que é que acontece? Quais estratégias utilizas?

$\checkmark$ Qual a tarefa mais característica do teu estudo?

$\checkmark$ Qual é o momento do teu estudo em que sentes mais facilidade ou dificuldade? Porquê? Como resolves?

Nesta etapa foi realizada também a reescrita por um escriba escolhido por cada aluno para realizar um novo texto na primeira pessoa, a partir da narrativa e das intervenções do participante.

Quinta etapa: apresentação de um projeto pessoal do aluno para a melhoria do seu processo de estudo e de autorregulação. Os alunos relatram como as reflexões e discussões realizadas no grupo mobilizaram novas estratégias autorregulatórias de como aprender a aprender.

Sexta etapa: finalização do projeto. O último encontro é marcado para fazer um balanço da incidência da formação nas experiências escolares e no processo de estudo de cada um.

\section{Resultados}

A análise dos dados foi realizada com base em procedimentos abertos exploratórios e múltiplas leituras dos achados, que caracterizam a técnica de análise de conteúdo (Bogdan e Bliken, 1994). A partir disso, emergiram três dimensões que evidenciram os momentos das etapas do ateliê, que teve como tema principal as estratégias autorregulatórias utilizadas na aprendizagem escolar e nas atividades de estudo. As três dimensões são: a construção da escrita de si, a compreensão do outro e o balanço na formação.

\section{Construção da escrita de si}

Essa dimensão permitiu identificar como os alunos fazem uso das estratégias autorreguladas na sua vida escolar. As histórias de vida são retratadas nas narrativas dos alunos para explicar as escolhas pessoais e os seus processos de formação.

A Figura 1 mostra um extrato retirado do texto (auto)biográfico do aluno A.L.P. e exemplifica como os aspectos pessoais estão relacionados ao modo de estudar e as aprendizagem escolares. A.L.P explica que é interessante estudar, principalmente quando estuda com pessoas que ele gosta, porém, em casa ele tem mais dificuldade de pegar um caderno e de se concentrar, como ele faz quando está na escola ou quando tem alguém o ensinando.

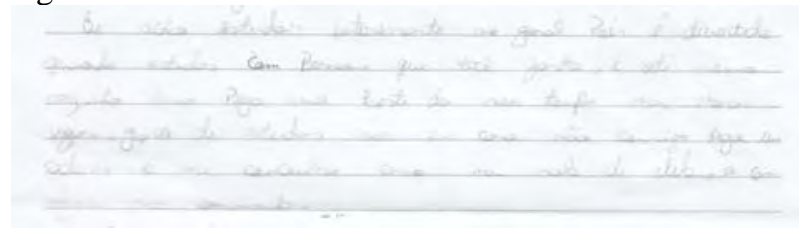

Figura 1: extrato do texto (auto)biografico do aluno A.L.P, realizado na terceira etapa.

A Figura 2 mostra as estratégias pessoais que A.R.G. utiliza quando precisa estudar para provas ou trabalhos. Nesse extrato ela enfatiza que não costuma estudar muito, mas quando estuda tenta ler e entender o conteúdo, e quando tem dificuldade pergunta para alguém ou procura na internet.

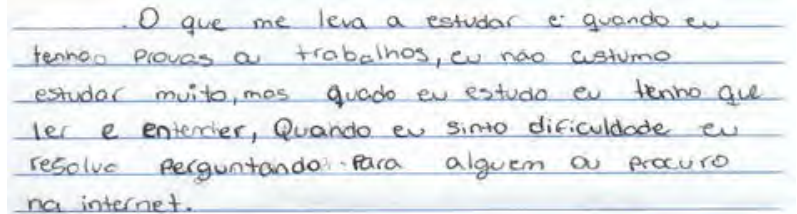

Figura 2: extrato do texto (auto)biográfico da aluna A.R.G, realizada na terceira etapa.

Esses exemplos mostram que as estratégias utilizadas pelos alunos em escolarização não é redutível às formas de organização institucionalizadas. Elas fazem transparecer toda a complexidade de experiências vividas cotidianamente e está, dessa forma, sempre ligada ao contexto de uma história escolar concreta. $\mathrm{Na}$ Figura 3, por exemplo, o aluno enfatiza a importância do ato de estudar para o futuro profissional e também relata suas dificuldades e suas prováveis causas. No extrato em questão ele relaciona o fato de ter repetido de ano com determinadas vivências do ambiente escolar, em especial os espisódios de "bullying” sofrido nos anos anteriores.

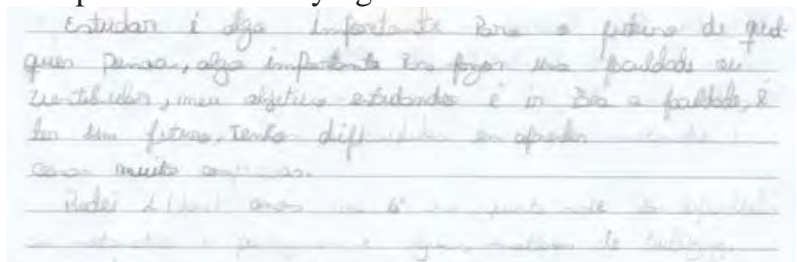

Figura 3: extrato do texto (auto) biografico do aluno A.L.P, realizada na terceira etapa.

Essa dimensão mostrou que as formas reflexivas (por meio das narrativas (auto)biográficas) que abordam as experiências com autorregulação da aprendizagem dos alunos, podem constituir um novo instrumento de mediação, no qual as construções biográficas podem se 
desenvolver e se transformar. Esses exemplos evidenciam a relação existente entre a aprendizagem autorregulada e os fatos (auto)biográficos e reiteram a posição de Nóvoa (2012) e Alheit e Dausien (2006), que dizem que sem biografia, não há aprendizagem e sem aprendizagem, não há biografia.

\section{Compreensão do outro}

A socialização das narrativas e as discussões sobre as questões relacionadas ao processo de autorregulação no estudo provocou uma mobilização em torno das estratégias utilizadas por cada um e das dificuldades encontradas durante esse percurso escolar.

O acompanhamento do processo de socialização que se internalizam nas histórias e experiências pessoal de cada um mostrou que o processo de estudo e de aprendizagem é realizado através de um conjunto de estratégias de autorregulacão evidenciado nas falas e nas escritas dos alunos e caracterizado pelos recursos salientados por Zimmerman e Risemberg (1997): comportamentais, cognitivos, metacognitivos e motivacionais.

As estratégias autorregulatórias comportamentais (como exemplificada na Figura 2) mais citadas pelo alunos são: i) a procura de apoio social (recorrendo à ajuda do professor, dos colegas) e ii) a estratégias de seleção de modelos (obtendo informações através da internet, site como wikipedia, entre outros).

As estratégias cognitivas e metacognitivas também são citadas como sendo utilizadas por todos os alunos, como por exemplo na fala de B.C. " tento prestar atenção e acompanhar a explicação do professor” e de E.B. "procuro observar as minhas dificuldades e focar meu estudo para prova da disciplina que não vou bem”.

Porém, fica evidente nas falas dos alunos, durante as discussões da etapa quatro, que para eles, a concepção estritamente cognitiva no processo de aprendizagem não é mais suficiente para obter bons resultados na vida escolar e até mesmo na futura vida profissional. A vontade e a motivação para aprender são aspectos tão importantes quanto os aspectos cognitivos.

As discussões realizadas durante o ateliê biográfico demonstram a falta de motivação quanto ao futuro pessoal e profissional de grande parte dos alunos que participaram desse estudo. Os alunos dessa escola provém de um meio social desfavorizado e não acreditam que o estudo é capaz de alterar esta condição. Na fala do aluno H.U.C. pode-se notar esse aspecto motivacional: "eu não gosto muito de estudar, mas minha mãe fala que é para eu terminar os estudos, pelo menos até o Ensino Médio, mas eu não acho que isso vai mudar a minha vida”.

Mesmo que os participantes da pesquisa apresentem objetivos coletivos, como por exemplo, ter um profissão, terminar o Ensino Médio, conseguir um bom emprego, percebe-se que o nível de motivação para alcançar esses objetivos estão muito baixo. Isto também pode ser percebido na fala de E.B. quando ela diz: “eu não tenho vontade e nem interesse em estudar, eu tenho muita preguiça, eu já falei para minha mãe que eu devo ter algum problema porque a única coisa que eu gosto de fazer é dormir”.
Todo aluno, em algum nível, é capaz de autorregular sua aprendizagem, ou seja, monitorar, regular e controlar sua cognição, motivação e comportamento tendo em vista seus objetivos (Sampaio, Polydoro \& Rosário, 2012). Contudo, a autorregulação pode ser menos eficiente ou ser realizada de modo inadequado, quando algum desses aspectos, como por exemplo a motivação, está alterado, o que pode levar a prejuízos na aprendizagem escolar (Zimmenman, 1998).

É observado, em todas as etapas do ateliê biográfico, que o componente motivacional é um aspecto importante que dá força e energia para sustentar o ato de aprender. Se $o$ aluno não valoriza suficientemente $o$ ato de aprender, se ele não tem vontade ou não se sente competente para isso, ele não será capaz de mobilizar as competências cognitivas, metacognitivas e comportamentais necessárias para evoluir no seu processo de escolarização.

Segundo Rosário (2015) e Boruchovitch (2010), pesquisas recentes têm mostrado que quanto mais o aluno avança na escolarização, mais o nível de motivação vai diminuindo. Esses autores evidenciam que, assim como os participantes dessa pesquisa, grande parte dos alunos do $9^{\circ}$ ano apresenta um nível muito baixo de motivação, quando comparados a outros alunos dos demais anos do Ensino Fundamental. No início do Ensino Médio, a tendência é aumentar novamente o nível de motivação, em virtude das provas de ingresso nas universidades (Rosário, 2015).

\section{Balanço na formação.}

No balanço da formação pelos alunos, durante as etapas cinco e seis, pôde-se notar que a partir desse ateliê houve um reconhecimento de si durante as escritas narrativas e reflexões orais dos recursos utilizados durante as atividades de estudos e de aprendizagem escolar dos alunos. Além do sentimento de fazer parte de um grupo, os alunos relataram que puderam aprender juntos, com a descrição das estratégias utilizadas por cada um e pelas histórias e projetos que compartilharam.

Essas estapas do ateliê biográfico auxiliaram no processo de autoformação e também na motivação desses alunos, já que eram instigados ao ato de autorreflexão, que envolve a autoavaliação e as atribuições causais, componentes da terceira fase do modelo cíclico da aprendizagem autorregualda de Zimmernan (2000). Este modelo envolve três fases cíclicas considerando o antes, durante e depois de uma atividade.

\section{Conclusão}

Com a realização desse ateliê, dentro de uma modalidade (auto)biográfica, foi possível desenvolver a estratégia de autoformação, centrada nas experiências escolares/de vida e mobilizadoras de reflexão. Ao elaborar uma narrativa escrita ou oral (auto)biográfica, o aluno interpreta a si, configura o mundo no presente, re-configurando o passado e prefigurando o futuro (Delory-Momberger, 2007). Nesse contexto, a narrativa desses alunos foi realizada em virtude do contexto presente, mas existe um sincretismo de cenas e situações do passado. A história de cada adolescente aparece como referência que dá forma ao presente e orienta o futuro. 
Os resultados evidenciaram que ao trabalhar com narrativas (auto)biográficas, tendo como viés a reflexão da escrita narrativa e oral dos sujeitos envolvidos, foi possível perceber a estreita relação entre o sentido individual dos alunos, através do fatos (auto)biográficos, e o que eles fazem para autorregular sua aprendizagem. A análise das etapas do ateliê mostrou que as experiências de vida de cada aluno revelam um nível diferenciado de autorregulação da aprendizagem e de apropriação das estratégias utilizadas no seu processo formativo. Isto é notado quando os alunos atribuem as dificuldades de organização e autorregulação da aprendizagem a variáveis pessoais, como por exemplo, ao fato de não gostarem de fazer as tarefas escolares ou de serem obrigados a frequentar as aulas. Assim, através da compreensão das estratégias autorreguladoras utilizadas na aprendizagem e do grau de envolvimento dos alunos nos ateliês biográficos de projetos, notou-se que a metodologia utilizada, de abordagem autobiográfica, foi adequada também nesse estudo com jovens alunos que estão na fase inicial do processo de escolarização. Por fim, as etapas vivenciadas nos ateliês ajudaram o jovem a compreender como ele se constrói enquanto aluno e como ele se auto-organiza para regular sua aprendizagem, para superar obstáculos e para se adaptar o mundo escolar e à vida.

\section{Referências}

Abrahão, M. H. M. B. (2003). Memória, narrativas e pesquisa autobriográfica. História da Educação, Pelotas: ASPHE//UFPel, p. 79-95.

Abrahão, M. H. M. B. (2004a). Pesquisa (auto) biográfica tempo, memória e narrativas. In: Abrahão, M. H. M. B.(Org.). A Aventura (Auto)Biográfica - Teoria \& Empiria. Porto Alegre: EDIPUCRS, p. 201-

224.

Abrahão, M. H. M. B. (2004b). Teacher Education and Outstanding Educators: Universal Characteristics. Journal of the International Society for Teacher Education - JISTE, v. 8, n. 1 , p. $48-56$.

Abrahão, M. H. M. B. (2005). The life history approach about outstanding educators to understand universial teacher's characteristics. Biography And Society, Göttingen, v. 1, p. 15-21.

Abrahão, M. H. M. B. (2008). Le récit autobiographique temps et dimensions de l'invention de soi. In: Souza, E. C. de (org). Autobiographies, Écrits de Soi et Formation au Brésil. Collection Histoire de Vie et Formation - Dirigée par Gaston Pineau, Paris: L'Harmattan, p. 125-146.

Abrahão, M. H. M. B. (2012). Pesquisar com professores na escola: contribuições da pesquisa dialógica para o desenvolvimento de aprendizagens autoerreguladas. In: Veiga Simão, A. M., Frison, L. M. B., \& Abrahão, M. H. M. B. Autorregulação da aprendizagem e narrativas autobiográficas: epistemologia e práticas. Porto Alegre: EDIPUCRS; Natal: EDUFRN; Salvador: EDUNEB, p. 113-154.

Abrahão, M. H. M. B., \& Frison, L. M. B. (2010). Narrativas (auto)biográficas de formação e o entrelaçamento com a autorregulação da aprendizagem. In: Abrahão, M. H. M. B. (Org.). (Auto)biografia e Formação Humana. Natal: EDUFRN; Porto Alegre: EDIPUCRS, p. 191-216.
Alheit, P., \& Dausien, B. (2006). Processo de formação e aprendizagens ao longo da vida. Educ. Pesqui.[online], vol.32, n.1, p. 177-197.

Basso, F.P., \& Abrahão, M. H. M. B. (2015). Professores como mediadores no processo de desenvolvimento de estratégias de autorregulação da aprendizagem. In Anais do II Colóquio de docência e diversidade na Educação Básica, Salvador, Bahia, p. 194-205.

Bogdan, R., \& Biklen, S. (1994). Investigação qualitativa em educação: uma introdução à teoria e aos métodos. Tradução de M. J. Alvarez, S. B. Santos e T. M. Baptista. Porto: Porto Editora, 1994.

Boruchovitch, E. (2010). A motivação no contexto escolar: implicações para formação de professores. In: Santos, B. S., \& Carreño, A. B. (Org.). A motivação em diferentes cenários. Porto Alegre: EdiPUCRS, p.119-128.

Cosnefroy, L. (2013). L’apprentissage autorégulé: entre cognition et motivation - déontologie et identité. Grenoble: Presses Univ. de Grenoble.

Delory-Momberger, C. (2006). Formação e Socialização: os ateliês biográficos de projetos. Educação e Pesquisa. São Paulo, v.32, n.2, p.359-371, maio/ago.

Delory-Momberger, C. (2007). Histoire de vie, processus de formation et théorie de l'apprentissage. In: Simonet-Tenant, F. Le propre de l'écriture de soi. Paris: Téraèdre.

Frison, L.M.B, \& Veiga Simão, A.M. (2011). Abordagem (auto)biográfica: narrativas de formação e de autorregulação da aprendizagem revelados em portfólios reflexivos. Revista Educação/PUCRS. Porto Alegre, v.34, n.2.

Josso, M-C. (2004). Experiências de vida e formação. São Paulo: Cortez.

Nóvoa, A. Prefácio: a experiência é uma invenção. In.Veiga Simão, A. M., Frison, L. M. B., \& Abrahão, M. H. M. B. Autorregulação da aprendizagem e narrativas autobiográficas: epistemologia e práticas. Porto Alegre: EDIPUCRS; Natal: EDUFRN; Salvador: EDUNEB, p. 113-154.

Mottier, L. L. (2013). Recherche collaborative sur les pratiques de régulation formative en classe: questionnement épistémologique critique. Actes du colloque Recherches Actions Collaboratives (RAC).

Dijon, France.

Passeggi, M. C., Souza, E. C., \& Vicentini, P. P. (2011). Entre a vida e a formação: pesquisa (auto)biográfica, docência e profissionalização. Educ. rev. [online], vol.27, n.1, pp. 369-386.

Rosário, P.S.L. (2015). Autorregulação da aprendizagem em debate (painel internacional). I Seminário Internacional Teoria Social Cognitiva em Debate. Campinas-SP.

Sampaio, R.K.N., Polydoro, S.A.J., \& Rosário, P.S.L. (2012). Autorregulação da aprendizagem e a procrastinação acadêmica em estudantes universitarios. Pelotas. v. 42, pp. 119 $-142$.

Zimmerman, B. (1998). Developing self-fulfilling cycles of academic regulation: An analysis of exemplary instructional models, Cap. 1. In: Zimmerman, B.; Schunk, D. Self-regulated learning: from teaching to self-reflective practice, The Guilford press, New York/London.

Zimmerman, B. J., Bonner, S., \& Kovach, R. (2000). Des apprenants autonomes: autorégulation des apprentissages. (Pagnoulle. C., \& Smets. G, trad.). Bruxelles: De Boeck.

Zimmerman, B., \& Risemberg, R. (1997). Becoming a self-regulated writer: A social cognitive perspective. Contemporay Educational Psychology, v. 22, p. 73-101. 